\title{
An Imaginative Person's Guide to Objective Modality
}

\begin{abstract}
.
Imagination is a source of evidence for objective modality. It is through this epistemic connection that the idea of modality first gains traction in our intellectual life. A proper theory of modality should be able to explain our imagination's modal epistemic behaviors. This chapter highlights a peculiar asymmetry regarding epistemic defeat for imagination-based modal justification. Whereas imagination-based evidence for possibility cannot be undermined by information about the causal origin of our imaginings, unimaginability-based evidence for impossibility can be undermined by information about the causal origin of the unimaginability. It is argued that an acceptance of S4 over S5 as the true logic for objective modality best explains this epistemic asymmetry.
\end{abstract}

\section{Our Modal North Star}

Chance is an objective feature of reality. But it's a puzzling feature. It isn't even immediately clear how we might begin to theorize sensibly about chance. We need some kind of methodological anchor to set us on a proper path and tell us what to look for.

Lewis has a suggestion. In “A Subjectivist's Guide to Objective Chance” (1980), he approaches this question by articulating a rational norm governing the relation between credence and chance, a norm known as the Principal Principle (PP). It's a principle that tells us how a rational person's credences should correlate with her beliefs about objective chances. Roughly put, it says that our credences should track our beliefs about objective chances. We will get into the detail of PP shortly. But the methodological point for now is that, even if we don't know what objective chance really is, we clearly have a rudimentary conception of objective chance already; otherwise, we wouldn't even 
be asking questions about the nature of objective chance. The notion has already entered our intellectual life somehow, playing a certain cognitive role. Whatever metaphysics of objective chance we come up with, it shouldn't deviate significantly from this rudimentary grasp; otherwise, we risk simply changing the subject. Lewis argues that PP is important because it captures our rudimentary grasp of objective chance. If we have a handle on the idea of objective chance at all, it stems from our thoughts about how certain we should be about things. A good metaphysics of objective chance must therefore be able to explain why chance and ideal credence correlate in the way PP says they do. PP serves as an Archimedean point that guides our search for a theory of chance.

This paper isn't primarily about objective chance (though it will play a role). My main goal is to show what we can do with the epistemic connection between imagination and metaphysical modality by mimicking what Lewis did with the relation between credence and chance.

Assuming that there is objective, metaphysical modality, it's hard to wrap our heads around what modal reality is supposed to be. Drastically different hypotheses have been offered, from views that appeal to disconnected spacetime regions (Lewisian possible worlds) to views that appeal to powers of actual entities (e.g., Jacobs 2010). The logical space of admissible options is so vast that it can be intellectually crippling. Fortunately, like the concept of objective chance, the concept of objective modality isn't a theoretical invention. The idea of possibility and necessity has already entered our intellectual life, playing a cognitive role, a role related to our imagination.

Is a talking donkey metaphysically possible? I try to imagine a donkey talking and succeed. I thereby conclude that it is possible. Is it metaphysically possible for something to be all green and all red? I try but cannot imagine a surface colored that way. I thereby conclude that it is metaphysically impossible. It's fairly common to move from what one can imagine to what is possible this way. It might be controversial to say that imaginability entails possibility (and that unimaginability entails impossibility). But it's relatively safe to assume that imagination provides defeasible evidence for 
possibility (and that unimaginability provides defeasible evidence for impossibility). In this essay, I'm going to assume that imagining something provides justification for believing in its metaphysical possibility and a failed attempt to imagine something provides justification for believing in its metaphysical impossibility. ${ }^{1}$

Now I want to say something slightly more controversial. Whereas imagination is not our only epistemic route to modality, the epistemic connection between imagination and modality is special. This connection is how the idea of objective modality enters our intellectual lives in the first place. It captures our rudimentary grasp of objective modality in the same way PP captures our rudimentary grasp of objective chance. My contention is that, if the idea of objective possibility and necessity has any intellectual traction on us to begin with, it stems from what we can or cannot imagine. This modal epistemic connection can serve as an intellectual anchor that guides our search for a theory of modal reality in the same way PP sets us on the right path in search for a theory of objective chance. So, a proper theory of objective modality should be able to explain the way our imagination provides evidence for modal claims intuitively.

By "the way our imagination provides evidence for modal claims", I mean not only how our imagination succeeds in justifying modal claims but also how imagination fails to justify modal claims in certain cases (i.e. how imagination-based justification may be epistemically defeated). This essay is particularly interested in the latter. ${ }^{2}$ The goal of this essay is to argue that, using the imaginationmodality connection as our Archimedean point and attending particularly to how imagination-based

\footnotetext{
${ }^{1}$ Of course, there are skeptics, e.g., Van Inwagen (1998). But the goal of this essay isn't to address the skeptics. I also limit myself to current imaginings. I set aside whether having been able to imagine something in the past counts as evidence for possibility.

2 The emphasis on the epistemic defeat is what sets my project apart from Peacocke's (1999), which seeks to integrate the epistemology and metaphysics of modality.
} 
modal justification gets defeated, we have good reason to think that the proper logical structure of modal reality is S4 instead of S5.

\section{The Curious Case of Etiological Defeat}

Let's focus on the justification for possibilities and set aside justification for impossibilities for the moment. Imagination-based modal justification may be presented as epistemically analogous to perceptual justification, as Yablo puts it:

Without suggesting that Hume would go quite so far, I take the idea to be that conceiving is in a certain way analogous to perceiving. Just as someone who perceives that $\mathrm{p}$ enjoys the appearance that $\mathrm{p}$ is true, whoever finds $\mathrm{p}$ conceivable enjoys something worth describing as the appearance that it is possible. In slogan form: conceiving involves the appearance of possibility. $(1993,5)^{3}$

And Geirsson, for example, appeals to this analogy in response to those who are skeptical of imaginability's relevance for modal justification because of its fallibility:

That I can imagine a scenario where something appears true while it cannot be true does not mean that conceivability does not carry with it justification of beliefs of what is possible. It is a general feature of justification that it does not guarantee truth, and that one can be justified in believing what is false. For example, perceptual beliefs are typically justified although they do not guarantee truth. $(2005,296)$

\footnotetext{
${ }^{3}$ Yablo and Geirsson don't distinguish conceivability and imaginability.
} 
If I perceive a piece of broccoli, I have prima facie justification for believing that there is a piece of broccoli. In the same way, my imagining a talking donkey gives me prima facie justification for believing that a talking donkey is possible. Imagination is like perception of the modal space.

Although perception can be used as an analogy to illustrate the sense in which imagination provides prima facie modal justification, there are significant differences. For our purpose in particular, epistemic defeat for perceptual justification and imagination-based modal justification don't seem to work the same way.

My perceiving a spider gives me prima facie justification to believe that there is one. Such justification is defeasible. Here is one way my perceptual justification may be defeated: being told that I just consumed some hallucinogenic mushrooms. The information that I have consumed a hallucinogenic substance undermines the support that my perceptual experience provides to my belief that there is a spider. This kind of epistemic defeater is standardly called an undermining or undercutting defeater. (This is in contrast to rebutting defeaters, which are evidence against the belief at stake directly, not the epistemic force of the prima facie justification involved. $)^{4}$

More specifically, the kind of undermining defeater involved in this scenario is etiological. The justificatory force of my perception is undermined by information about the causal origin of the perception. This is worth mentioning because not all undermining defeaters are etiological. For example, in the well-known fake barn case, if I'm told about the existence of the numerous fake barns in the area, my perceptual justification for thinking that I'm standing in front of a barn is undermined, yet there is nothing wrong about the causal origin of my perceptual experience.

\footnotetext{
${ }_{4}^{4}$ The distinction between undermining and rebutting defeaters is due to Pollock (1987). See also Sturgeon (2012) and Melis (2014) for further analysis of the distinction.
} 
By contrast, unlike perceptual justification, it seems that etiological undermining defeaters don't work for imagination-based modal justification for beliefs about possibility. Suppose I'm justified to believe that a talking donkey is a metaphysical possibility because I imagined one. Say I'm told that I started imagining and fantasizing about talking donkeys because someone slipped something into my drink. Without the drug, being an uptight person (or perhaps I suffer from some kind of aphantasia), I wouldn't be able to imagine such nonsense even if I tried. Does this information about the causal origin of my imagining undermine the modal justification my imagining provides? I'm inclined to say no. It would have undermined my perceptual justification for believing that there is an actual talking donkey if the substance caused me to see talking donkeys. But as long as I'm really imagining talking donkeys, I don't see how that etiological information undermines my justification for believing that talking donkeys are possible in light of my imagination.

The same is true even if the source of my imagination is more invasive. Perhaps my imagining a talking donkey is caused by a neurosurgeon stimulating certain areas of my brain. Whereas this kind of information would undermine perceptual justification about what is actual, it doesn't undermine the modal justification provided by my imagination. Assuming that imagination provides modal justification, it provides modal justification regardless of the imagining's causal origin. ${ }^{5}$

This disanalogy between imagination-based modal justification and perceptual justification alone is interesting and calls for an explanation, but the puzzle runs deeper. Although it seems that

\footnotetext{
${ }^{5}$ One might argue that perceptual justification is based on a perceptual experience's causal connection with the perceived in normal circumstances. That isn't the case for imagination-based justification about possibility. Hence, etiological information may defeat perceptual justification but not imagination-based justification about possibility. I don't know that this is a good explanation. I'm skeptical of this view about perceptual justification because of the New Demon Problem: although perceptual experience in the Matrix doesn't provide knowledge, it should still provide justification.
} 
there is no etiological undermining defeater to modal justification for possibility based on our imagination, modal justification for believing that something is impossible based on a failed attempt to imagine something can be undermined etiologically. For example, if I find myself incapable of imagining something, I have prima facie justification for believing that that thing is impossible. But if I'm then told that my imagination's failure is due to a brain injury, that information would undermine my modal justification for believing that that thing is impossible. ${ }^{6}$

Recognizing this asymmetry in etiological defeat can play an important role in modal epistemological discussions. For example, Kung (2010) states that non-sensory imagination - unlike sensory imaginations - is far too liberal to be of value for modal justification. How does he argue that non-sensory imagination is too liberal? Kung's strategy is to first identify what constrains our capacity to imagine something (i.e., what stops us from being able to imagine something) and then argue that such constraints are not relevant to objective modality. Since the only constraints on imagination are not relevant to what is objectively possible, he concludes that our power of imagination isn't sufficiently constrained to provide evidence for objective possibilities.

Notice that learning about what constrains our capacity to imagine is simply to obtain information about the source of our inability to imagine something. This kind of information can indeed undermine justification for believing that something is impossible based on what we cannot imagine. If Kung has succeeded in showing that the factors that prevent us from imagining something - in a non-sensory way - are irrelevant to objective modality, he may have offered a general reason to undermine the legitimacy of using our inability to non-sensorily imagine as evidence

\footnotetext{
${ }^{6}$ Information about the origin of one's unimaginability can undermine modal justification for impossibility even if it doesn't involve brain injury. See Levin (2011) for a discussion of the epistemic significance of imaginative resistance as a source of unimaginability.
} 
for the impossibility. However, even if we grant him that, given what we have said about the asymmetry that etiological defeaters work for undermining justification for impossibility based on our inability to imagine but do not work for undermining justification for possibility based on our imagination, it remains unclear that we should jump to any conclusion about justification for possibility based on what we can and do imagine. ${ }^{7}$

There is certainly much more to be said about the application of this epistemological asymmetry. One might even question the reality of this asymmetry. In this essay, I take this apparent asymmetry at face value as a starting point. My goal is to show that, assuming as a premise that this asymmetry in the imagination-modality connection obtains, and assuming as a premise that the imagination-modality connection is an Archimedean point for theorizing about modality, this asymmetry presents a substantive constraint upon our view about the modal reality.

\section{Lewisian Chance-Credence Norm}

To explain the asymmetry regarding epistemic defeat for modal justification, we need to explain two facts:

[Etiological Immunity] modal justification about possibility based on imagination is not defeasible etiologically; and

[Etiological Vulnerability] modal justification about impossibility based on inability to imagine is defeasible etiologically.

\footnotetext{
7 See Lam (2018) for a further discussion.
} 
There is a ready explanation for [Etiological Immunity] based on Lewis's PP. So, let's take a closer look at this chance-credence norm first.

Credence and chance are different things. Yet, if one's credence about something is supposed to be reflected in one's rational betting behavior, then it's plausible to think that there is some rational connection between the two. After all, our rational betting behaviors should be somehow sensitive to what the chances are.

PP says that how certain we are about a proposition (i.e., our credence) should match the objective chance of that proposition. Or, in technical terms that some philosophers somehow prefer: a subject S's credence for a proposition Q conditional on the proposition that the objective chance of $\mathrm{Q}$ is $\mathrm{x}$ should be equal to $\mathrm{x}$. So, if I believe that there is 0.3 chance that it will rain, my credence for the fact that it will rain should also be 0.3 .

This is of course a simplification of the matter. Lewis argues that there is what he calls inadmissible evidence that, when present, breaks the rational connection between credence and objective chance. To put it in terms of notation introduced earlier, Lewis explains inadmissible evidence about $\mathrm{Q}$ as a piece of evidence that is directly about Q - not by being a piece of evidence about chance.

Here's an example to illustrate the idea. Say a coin, which I believe was a fair coin, was flipped in my absence. A friend tells me that it landed heads. Notice that my friend's testimony is evidence for the proposition that the coin landed on head. It isn't evidence about the chance of it landing heads. The testimony is therefore inadmissible evidence. (By contrast, information about the past frequency of the coin landing heads would be evidence about the chance of it landing heads. Such information would be admissible evidence.) In this case, despite my believing that the coin was fair and had a 0.5 chance of landing heads, I am not thereby rationally required to have 0.5 credence that the coin was going to land heads. Given the testimonial justification for believing that it has landed 
heads, my rational credence for that should be higher than 0.5 (see Lewis 1980, 265). Having inadmissible evidence (i.e. the testimony from my friend) breaks the chance-credence connection. So, what PP says isn't that our credence should track what we believe to be the chance of things no matter what. The thought is that credence should track objective chance given any admissible evidence and admissible evidence alone.

It's contentious how "admissibility" is to be analyzed more rigorously and, accordingly, what exactly is inadmissible. On one occasion, Lewis argues that information directly about the future is all inadmissible (e.g., a crystal ball that reveals the future directly) and information about the past and probabilistic laws of nature are all admissible. But the example about testimonial evidence indicates that some information about the past can be inadmissible evidence that breaks the chance-credence norm. Different philosophers have since then offered different ways to formalize or standardize the idea. ${ }^{8}$

I'm not going to engage in those debates in this essay because, for those who accept that imagination provides modal justification, imagination is admissible evidence. This might be surprising to some. One might be tempted to think that, since perceptual evidence is not evidence about chance and therefore inadmissible, ${ }^{9}$ if we model imagination-based justification about possibility with perceptual justification about actuality, perhaps we should think that imagination-based modal evidence is inadmissible evidence as well. But notice: the fact that a state of affairs $\mathrm{p}$ is possible just is the fact that there is a non-zero chance that p. Evidence about possibility is evidence about chance, unlike perceptual justification. Therefore, evidence for possibility is admissible. Since modal

\footnotetext{
${ }^{8}$ For example, see Hall (1994), Thau (1994), Vranas (2004), Ismael (2008), Pettigrew (2013).

9 This is unless one thinks of our minds as predictive systems through and through, see Clark (2013).
} 
evidence is admissible and doesn't break the chance-credence normative connection, the exact analysis of admissibility doesn't make significant difference to what I'm going to say.

\section{Explaining Etiological Immunity}

Let's take a step back from modal justification and think about evidence more generally. To receive information as evidence for $\mathrm{p}$ is to accept information that, all else being equal, should boost one's credence for $\mathrm{p}$. If a piece of information doesn't make it rational to be more certain about $\mathrm{p}$, that piece of information isn't evidence for $\mathrm{p}$.

A rational person's credence at a time should satisfy the axioms of probability calculus. So, a rational person's credence updating should be governed by Bayes' Theorem (assuming $\mathrm{P}(\mathrm{B})>0$ ): $\mathrm{P}(\mathrm{A} \mid \mathrm{B})=\mathrm{P}(\mathrm{B} \mid \mathrm{A}) \mathrm{P}(\mathrm{A}) / \mathrm{P}(\mathrm{B})$. This dictates that, if $\mathrm{P}(\mathrm{A})=0$, there is no $\mathrm{B}$ such that $\mathrm{P}(\mathrm{A} \mid \mathrm{B})$ is nonzero. In other words, if a rational person is absolutely certain that A isn't the case so that $\operatorname{Cr}(\mathrm{A})=0$ (where Cr stands for the person's credence function at a time), then no information should be able to boost her credence over zero. Since evidence boosts credence, a rational person should never think that there is evidence for $\mathrm{A}$ if she begins with $\operatorname{Cr}(\mathrm{A})=0$. On the flip side, if she thinks that there may be evidence for A, her credence for A should be non-zero.

Now let us consider the following state of affairs:

\section{Z: it is possible that $\psi$.}

If a rational person thinks that there is any evidence for $Z$ at all, her credence for $Z$ must be non-zero (due to Bayes' Theorem). Then the chance-credence norm PP dictates that she ought to believe that $Z$ has a non-zero chance. It would have been irrational of her to believe that there is no chance for $Z$ yet have some degree of belief that $Z$ is the case. As I have stated in the previous section, to say that 
something is possible just is to say that that thing has a non-zero chance. In other words, this rational person, who ought to believe that there is a non-zero chance that $Z$, ought to believe that it is possible that $Z$; otherwise, she shouldn't believe that there can be any evidence for $Z$ at all.

Here is a modal logic principle:

[Possibly Possible] If it is possibly possible that $\mathrm{p}$, then it is possible that $\mathrm{p}(\diamond \diamond \mathrm{p} \rightarrow$ $\diamond \mathrm{p})$

To think that it's possible that $Z$ is to think that it is possibly possible that $\psi$. The principle Possibly Possible] requires that, if a rational person believes that it is possible that $Z$ (hence $\diamond \diamond \psi$ ), she ought to also believe that it is possible that $\psi$. So, based on Lewis's PP and [Possibly Possible], a rational person who thinks that there is evidence that it is possible that $\psi$ ought logically to believe that it is possible that $\psi$.

Notice that this is a very substantive claim. That there is evidence for $\mathrm{p}$ doesn't normally entail that $\mathrm{p}$ even for an ideal rational agent. When a rational person hears her cat vomiting, that auditory experience is evidence for the fact that her cat is vomiting. That doesn't, however, entail that her cat is vomiting. The perceptual evidence is non-conclusive. What we have shown based on PP and [Possibly Possible] is that evidence for statements about possibility works differently. That there is evidence for a statement about something's being possible entails that the statement is true. In other words, there is only conclusive evidence for possibility. If we think that imagination provides evidence for possibility at all, we ought to think that it's conclusive evidence.

This explains [Etiological Immunity]. If I managed to imagine a talking donkey, I ought to believe that it's possible for there to be talking donkeys. Since entailment is monotonic, no extra 
information can undermine the evidence for the possibility of a talking donkey. That is why it should not change anything to learn that my imagination is triggered by a surgeon stimulating my brain.

\section{Defeating an Appeal to Conclusive Evidence}

My explanation of [Etiological Immunity] is based on my demonstrating that one's imagining something entails its possibility in virtue of PP and [Possibly Possible]. I reckon that most would find the entailment claim intuitively questionable. Unlike Hume, most philosophers who endorse imagination-based modal justification find it too strong to claim that imagination entails possibility. Even Chalmers (2002), who argues that conceivability entails possibility, only defends the view that ideal conceivability entails possibility.

One can see where the hesitation comes from. We appear to imagine things that are impossible. For example, here's a mathematical statement: there is at least one prime number between 155921 and 360653. Given how many numbers there are between 155921 and 360653, one might think that one can imagine finding a prime number between them. The truth is, there are no prime numbers between them. Assuming that mathematical statements have their truth-value necessarily, it's necessary that there are no prime numbers between 155921 and 360653. So, as a source of evidence for possibility, our imagination seems obviously fallible. And that seems to undercut my explanation for [Etiological Immunity].

Actually, my explanation of [Etiological Immunity] is compatible with our appeal to imagination for modal justification being fallible. To illustrate why, let's consider a mathematical proof. A proof is conclusive evidence for a mathematical statement. If a person has a proof for a mathematical statement $\mathrm{p}$, that is the end of the matter. One doesn't go on to weigh the strength of various evidence for $\mathrm{p}$ after that. But this doesn't mean that, when she presents her justification for $\mathrm{p}$ by constructing a proof, she is infallible. There can still be an epistemic defeater for her justification for 
accepting $\mathrm{p}$. If information becomes available that indicates that what she presented was in fact not a proof for $\mathrm{p}$ at all (perhaps there was a mistake in her attempt to construct a proof), her justification would be nullified. This information shows that she has misidentified something as a proof and hence as evidence for p. Mathematical proofs are conclusive but our ability to identify proofs is fallible. As Peacocke (2003) rightly points out:

[We should] distinguish two kinds of defeasibility, which I will call defeasibility of identification and defeasibility of grounds. A ground for accepting a proposition can be conclusive even though our entitlement to believe that we have identified such a ground is defeasible. Identifying something as a conclusive ground is one thing; its being a conclusive ground is another. (30)

Let us call this an Identification Defeater.

To think that evidence for possibility, focusing on imagination for our purposes, must be conclusive is compatible with our fallibility because our ability to identify relevant imaginings is fallible. For example, I could think that I was imagining finding a prime number between 155921 and 360653, but all I was in fact doing was imagining my reaction to finding such a number instead of imagining there being such a number. (For example, I might react by thinking out loud, "Huh, so there is a prime number between 155921 and 360653. I wonder whether there is a second one.”) So, perhaps, our imaginings are modal epistemologically fallible not because imagination is inconclusive, just like mathematicians are fallible not because mathematical proofs are inconclusive.

This echoes much of what we see in debates about metaphysical modality. Consider the claim that light is a stream of photons, which Kripke considers necessary a posteriori if true. There is an 
anti-essentialist concern that light might have turned out to be something else. We could imagine a scenario where there are photons firing yet we see no light. Kripke's response is:

Imagine a situation in which human beings were blind or their eyes didn't work. They were unaffected by light. Would that have been a situation in which light did not exist? It seems to me that it would not. It would have been a situation in which our eyes were not sensitive to light. [...] Even if all people had had awful vestigial growths and just couldn't see a thing, the light might have been around; but it would not have been able to affect people's eyes in the proper way. (1980, 129-130)

Kripke's point is that the anti-essentialists are mistaken about the content of their imagining. They are not, as they thought they are, imagining a scenario with photons but no light. Instead, they are imagining a scenario where there is light but people have no ability to detect light.

The question is: why go this route? If imagination is inconclusive modal evidence, Kripke could have simply said that the anti-essentialists have indeed imagined a scenario in which there is a stream of photon and no light, but maintained that imagination is defeasible and this is a case in which light remains essentially a stream of photon despite what we imagine. Note that it is not at all clear that this is a weaker defense than saying that the anti-essentialists are wrong about the content of their own imagining: they aren't really imagining light being something other than streams of photons, Hesperus not being identical to Phosphorus, water being something other than $\mathrm{H}_{2} \mathrm{O}$, etc.

The same applies to the Kripkean defense of dualism about phenomenal qualities. Kripke states that it is conceivable for us to have C-fibers firing without the feeling of pain. Central to Kripke's defense is the argument that, since we couldn't have been mistakenly imagining something else when we appeared to be imagining ourselves to have C-fibers firing without the feeling of pain (due to our 
direct reference to both), and since identity is necessary, we should conclude that pain is not C-fibers firing.

A similar question arises: what is the point of focusing on arguing whether one could have been mistaken about the content of one's imagination? The question wouldn't have been even half as pressing if Kripke alone chooses to go down this road. On the contrary, a huge portion of the literature - from both dualists and physicalists - on philosophical zombies has been devoted to pinning down a proper characterization of the content of the relevant imaginings (e.g., the analysis of phenomenal concepts). This is puzzling. If imagination is inconclusive evidence for possibility, a physicalist can simply concede that we can imagine pain and C-fibers firing coming apart yet note that this is just one of those cases in which our imagination gets modality wrong. It's unclear how much extra dialectical mileage, if any, dualists can gain from cornering physicalists into conceding that we couldn't have been imagining something else when we imagine zombies. ${ }^{10}$

All this makes sense, however, with what we said about [Etiological Immunity]. If imagination is evidence for possibility, imagination entails possibility; and thus the only way to defeat an appeal to imagination as evidence for possibility is by showing that the alleged imagining in fact didn't happen (i.e., presenting an Identification Defeater). That's why essentialists need to argue that the anti-essentialists aren't really imagining light and photon streams coming apart. And that's why it's a challenge physicalists need to take seriously if dualists are right that there is no plausible way to reinterpret what dualists claim to be an imagining about zombies into an imagining about something else (or not as an instance of the relevant kind of imagining at all).

The result is what Kung (2016) calls the Error Theory about imagination, which says that we cannot imagine what is impossible and, if we thought we have imagined something impossible, it is

\footnotetext{
${ }^{10}$ For more examples of debates that appear to assume that imaginability implies possibility, see Kind (2016).
} 
an error and something else must have happened. Kung objects that, if we set our modal epistemology aside and try to just honestly describe our imagination, it is far more intuitive to acknowledge that we can imagine the impossible. ${ }^{11}$

To reinterpret and restrict intuitive cases of imaginings as the Error Theory suggests is, according to Kung, to adopt a "telescopic view of imagining" that uses "imagine" as a success term like "see" $(2016,91)$. One cannot see what does not exist because there is nothing to see; similarly, one cannot imagine what is impossible because there is nothing to imagine. What one ends up with is a "modal-conclusion-first reasoning" (ibid, 104): one attributes imaginings (to oneself and others) according to one's prior modal beliefs. Kung thinks that doing so snuffs out any hope of using imagination as a guide to possibility.

My appeal to Identification Defeaters is to embrace the Error Theory. One thing that makes Kung suspicious of the Error Theory is that philosophers like Kripke offer no clear motivation for the view that flies in the face of our ordinary self-ascriptions of imaginings. And it isn't immediately clear that we need to use "imagine" as a success term to treat imagination as a guide to possibility.

Now we know better. There is an independent reason to accept the Error Theory. It follows from two highly intuitive principles: Lewis’s PP and [Possibly Possible]. We obtain a neat explanation for [Etiological Immunity] as a result.

Note that even those who reject the Error Theory should accept that our self-ascriptions of imaginings are fallible. Attitude ascriptions aren’t immune to the same cost-benefit analysis that all our other beliefs are subjected to. One may refuse to revise our ascriptions of imagining as the Error

\footnotetext{
11 See also Kind (2016) and Priest (2016: 2658-2659). Priest proposes a logic for imagination that allows impossible worlds to be imagined. Embracing the Error Theory, I clearly don't accept this as the logic for imagination. Yet, none of this prevents us from accepting a semantics that includes impossible worlds for modeling thoughts about modality itself. For simplicity's sake, however, I'll focus on normal modal logic for that is the standard treatment for objective modality.
} 
Theory requires. The cost is having to reject either PP or [Possibly Possible] and leave [Etiological Immunity] unexplained. People may value the trade differently. But the Error Theory is not obviously getting a bad bargain. Surely, it opens the gates to some "modal-conclusion-first reasonings" that revise our imagining ascriptions based on modal facts external to a theory of imagination. That doesn't mean we can no longer rely on imagination as a guide to possibility. It just means using imagination to reach possibility is a holistic enterprise. One person's modus ponens is another person's modus tollens. And I don't see why taking a person's self-report of imaginings seriously implies, as Kind $(2016,347)$ seems to suggest, that revisions to our imagining ascriptions must be based entirely on factors internal to a theory of imagination.

\section{Explaining Etiological Vulnerability}

Suppose we are satisfied with the explanation for [Etiological Immunity]. What is possible and what is impossible are closely tied logically. It's natural to wonder whether what I argued for about evidence for possibility would logically lead to something similar about evidence for impossibility. But that would be bad news given that we want to explain [Etiological Vulnerability].

Here's a parallel argument for the conclusiveness of evidence for impossibility. To have evidence that a state of affairs is impossible is to have evidence that the negation of that state of affairs is necessary. Let's consider the following state of affair:

\section{T: it is necessary that $\psi$.}

Again, a rational person's credence is governed by Bayes' Theorem. So, for a rational person to have evidence for $T$, her credence for $T$, i.e., $\operatorname{Cr}(T)$, has to be non-zero. The Principal Principle then says that she ought to believe that there is a non-zero chance that $T$ is the case. The fact that $T$ has a 
non-zero chance just is the fact that $T$ is possible. Hence, a rational person ought to think that it's possible that $T$, i.e., that it is possibly necessary that $\psi$, if she thinks that there is evidence for $T$. Here is a modal logic principle:

[Necessarily Possible] If it is possible that $\mathrm{p}$, then it is necessarily possible that $\mathrm{p}$ $(\diamond \mathrm{p} \rightarrow \square \vee \mathrm{p})$

[Necessarily Possible] is logically equivalent to its contrapositive: $\sim \square \vee p \rightarrow \sim \vee_{p}$, which is, in turn, equivalent to $\diamond \square \sim \mathrm{p} \rightarrow \square \sim \mathrm{p}$ and, hence, $\diamond \square \mathrm{p} \rightarrow \square \mathrm{p}$ (by substitution).

Since PP requires that a rational person who believes that there is evidence for $T$ to believe that it's possibly necessary that $\psi$, it requires her to believe that it's necessary that $\psi$. As I mentioned, every statement about necessity just is a statement about something being impossible. Therefore, a rational person is required to think that, if there is any evidence that something is impossible at all, that evidence is conclusive. If a rational agent thinks that a failed attempt to imagine that $\mathrm{p}$ is evidence that $\mathrm{p}$ is impossible, she ought to think that her failed attempt is conclusive evidence that $\mathrm{p}$ is indeed impossible.

But that cannot be if we want to think about objective modality in a way that is in line with the modal epistemic behavior of imagination, which includes the way imagination-based modal justification can/cannot be undermined by defeaters. Specifically, although one's inability to imagine that $\mathrm{p}$ is evidence that $\mathrm{p}$ is impossible, that evidence can be undermined by information about the source of such inability - [Etiological Vulnerability]. Learning that your inability to imagine that $\mathrm{p}$ is due to a brain injury defeats your inconceivability-based modal justification for thinking that it is impossible that $\mathrm{p}$. To do so, this defeater doesn't need to suggest that you aren't really incapable of imagining p; that is, evidence for impossibility can be defeated by something other than an 
Identification Defeater. Evidence for possibility ought to be conclusive; evidence for impossibility need not be. To preserve this epistemic asymmetry, something in this parallel argument must go.

Here is my hypothesis. The best way to explain [Etiological Immunity] without sacrificing [Etiological Vulnerability] is to accept the principle [Possibly Possible], which is key to my explanation of [Etiological Immunity], while giving up the principle [Necessarily Possible], which is key to the argument for the conclusiveness of evidence for impossibility.

Doing so has substantive implications about the shape of the objective modal landscape. [Possibly Possible] is a theorem in the modal logic system S4 and [Necessarily Possible] is a theorem in the system S5 but not S4. In other words, to think of modal reality in a way that is in sync with the modal epistemic behavior of imagination, we better think of objective modality as being governed by S4 instead of S5. In S4, the accessibility relation among possible worlds is not symmetric. That means, $\mathrm{w}_{1}$ can be possible with respect to $\mathrm{w}_{2}$ without $\mathrm{w}_{2}$ being possible with respect to $\mathrm{w}_{1}$. But S4's accessibility relation is reflexive so that $\mathrm{w}_{2}$ is possible with respect to itself. As a result, it isn't logically guaranteed that what is possible with respect to one possible world must also be possible with respect to all other possible worlds.

This is a significant result. Philosophers have long been interested in the true logic for objective modality with S5 being the most popular system. But discussions on this topic often have the fates of S4 and S5 bundled together. Whereas there is a heated debate about whether S4 can be the true logic for metaphysical modality, the arguments involved are typically applicable to both S4 and S5. For example, Chandler (1976) and Salmon (1989) challenge S4 by arguing against [Possibly Possible] based on the assumption that, although it's possible for a material object to have a slightly different material constitution, it's impossible for it to have a massively different material constitution. There 
are ways to resist their objection. The details do not concern us here. ${ }^{12}$ The relevant point is that [Possibly Possible] is a theorem of both S4 and S5. The fates of S4 and S5 are therefore bundled together in this debate. By studying the modal epistemic behavior of imagination, we obtain an argument in favor of S4 against S5; and we do so without treating this conclusion simply as a result of our prior commitment to some substantive metaphysics of modality. ${ }^{13}$

\section{Overkill?}

My explanation of the modal epistemic behaviors of imagination specifically - [Etiological Immunity] and [Etiological Vulnerability] - is based on my argument about the way modal evidence in general behaves (or should behave). In this section, I'll discuss the potential worry that my approach overkills: while capturing the epistemic behaviors of imagination, my explanation implies the same for all sources of modal justification; and that may not be a desirable consequence.

Even those who acknowledge that imagination is a source of modal justification would never go so far as to say that it's the only source. There is no way I can cover every possible source of modal justification. ${ }^{14}$ What I'll do instead is to focus on testimonial justification for modal claims as a case study. My hope is that, by showing how my explanation's implication for testimonial modal

\footnotetext{
12 See Yagisawa (2017), Murray \& Wilson (2012), Roca-Royes (2011; 2006).

${ }^{13}$ For example, if one is committed to Armstrong's (1989) combinatorial metaphysics of modality, one would accept S4 and reject $\mathrm{S} 5$.

14 There are those who base their view on conceivability or imaginability (e.g. Yablo 1993, Geirsson 2005), there are those who rest their view on postulating the faculty of modal intuition (e.g. Bealer 2002; Fiocco 2007), there are those who rely on our implicit knowledge of the principle of admissible interpretations (e.g. Peacock 2003), and there are those who appeal to our power of forming supposition (e.g. Ichikawa \& Jarvis 2012).
} 
justification isn't as objectionable as it first seems, I can offer some assurance that it isn't implausible for my explanation to imply something similar for all forms of modal justification.

I'm justified in believing that there is a non-zero chance for a closed system's entropy to decrease over a limited time span. That is, it's possible that a closed system's entropy decreases over a limited amount of time. As someone who has no advanced knowledge in physics, my justification is based on textbooks: a textbook case of justification by testimony. (Pun intended!)

If we grant that there is testimonial justification for modal claims, and if I'm right that evidence for possibility must be conclusive, testimonial justification for claims about possibility must be conclusive, too. So, when I received testimony about the possibility of a decrease in entropy, I have conclusive evidence that it's possible.

As much as we think testimony can provide justification, we think that testimony is fallible, no matter what the testimony is about. We might, for example, receive information that the person delivering the testimony has been conducting her research with malfunctioning equipment. Similarly, on modal matters, we might learn that a person who testifies about chances and possibilities has been using a faulty calculator or doing modal logic wrong. In cases like this, it seems clear that whatever testimonial justification one gets is defeated. So, my explanation for [Etiological Immunity] seems to imply too much by implying that all modal evidence about possibility is conclusive.

My explanation is derived from PP and [Possibly Possible]. If one doesn't like the implication, one has to give up one of them. Either way, it's going to be a big theoretical sacrifice; and, on top of that, one will need to find another explanation for [Etiological Immunity]. The good news is, one doesn't have to do so. Saying that testimony about possibility is conclusive is not to say that appealing to testimony about possibility is indefeasible. Again, we should distinguish the conclusiveness of a piece of evidence and the defeasibility of one's appeal to evidence. 
To have testimonial justification is to be justified in believing something on the basis of taking another person's testimony at face value. To understand testimonial justification, we need to know what constitutes a piece of testimony. All that is uttered is not testimony.

To be a piece of testimony, the speaker must have the intention that the hearer believes what is said. For example, overhearing someone mumbling to herself doesn't count as a case of testimony in the relevant sense because she doesn't even intend to be heard. Whatever epistemic significance overhearing others' self-talk has, it's epistemologically unhelpful to lump it together with testimonial justification.

Furthermore, I want to argue that offering testimony is an inherently social phenomenon. What counts as testimony doesn't only depend on the testifier, but also depends on the hearer. Say I move to a community where no one speaks English. I cannot offer testimony by speaking English even if I sincerely intend to do so. It isn't that I produce testimony in English but the people fail to pick it up. What I say simply doesn't count as testimony because no one even acknowledges that I'm telling them something. ${ }^{15}$

As we said earlier, one can receive information indicating that what we thought was a mathematical proof is in fact not a mathematical proof. Similarly, testimonial justification is susceptible to Identification Defeaters. But, due to testimony's inherently social nature, Identification Defeaters for testimonial justification can happen in two ways.

\footnotetext{
${ }^{15}$ Instead of saying that testimony requires both the speaker's intention and the hearer's recognition, Lackey argues that we should distinguish two concepts of testimony: speaker testimony and hearer testimony (2006, 187). Since we're interested in testimony as a source of (modal) belief for the hearer, if we accept Lackey's distinction, we should focus on hearer testimony. What someone says doesn't constitute a piece of hearer testimony if the hearer doesn't reasonably recognize what the speaker says as conveying relevant information.
} 
First of all, you might receive information that indicates that what you received from the speaker was not intended to be a piece of testimony. Secondly, you might receive information that makes you outright refuse to even acknowledge that the speaker said anything meaningful to the conversation, shunning the speaker's contribution. Since testimony is partly constituted by the recipient's recognition, this effectively makes what the speaker said not even count as a piece of testimony.

Testimonial justification is fallible no matter what the testimony is about. This conflicts with my view's implication that testimonial justification for possibility must be conclusive, so the objection goes. I agree with the first claim but reject the second one. Just like the fallibility of imaginationbased evidence for possibility, the fallibility of testimony-based evidence for possibility can be explained by Identification Defeater. Hence, the fallibility of testimonial justification for possibility is compatible with my view, which implies that testimonial justification for possibility is conclusive.

Let me illustrate with an example. Say someone told me that certain subatomic process $L$ has a non-zero chance of happening. I thereby have testimonial justification for believing that $L$ is possible. But then I learn that that person makes things up all the time just to look knowledgeable. According to my view, the testimonial justification is nullified not because the new information undermines the justificatory force of the testimony; instead, it's because the new information gives me reason to simply ignore whatever that person said. With no recognition at all, what she says fails to be testimony and I therefore no longer have testimonial justification at all - not just a weakened or undermined one - that $L$ is possible.

One might wonder: Why should we describe defeaters for testimonial modal justification in the way I suggest? I'm not saying that we should. All I'm saying is that this is a coherent way to think about my explanation of [Etiological Immunity] and the fallibility of testimonial justification. The mere fact 
that testimonial justification for modal claims is fallible is therefore not an objection to my explanation. ${ }^{16}$

I focus on testimonial justification because it's a kind of justification that is most obviously fallible. But what I said applies to all sources of justification for beliefs about possibility. If it works for testimonial justification, it should work for other sources of evidence for possibility. For example, some argue that we have modal intuitions for what is possible. If that is the case, such intuitions should be conclusive evidence for what is possible. Having modal intuitions should be factive. Of course, we are fallible when we appeal to our modal intuitions (assuming that we have such a cognitive faculty). But like our appeal to imagination, that is because we are fallible in identifying instances of modal intuition.

\section{Conclusion}

Modal notions come into our intellectual life via the operation of our imagination. The epistemic connection between imagination and modality serves as a constraint upon our attempt to theorize about modality.

Attempts to integrate the epistemology and metaphysics of modality is not exactly new. My treatment of the subject is novel in its emphasis on observing the way epistemic defeaters work for imagination-based modal justification. I bring attention to an epistemic asymmetry: whereas information about the causal origin of our imagination cannot defeat imagination-based modal justification about possibility, information about the causal origin of our inability to imagine can

\footnotetext{
${ }^{16}$ Does my proposal make our appeal to testimony for modal justification circular? No, it just means working with testimony is a holistic business.
} 
defeat modal justification about impossibility. We should think about modal reality in a way that can account for this modal epistemic asymmetry.

I argue that the best explanation for the asymmetry is by accepting Lewis's Principal Principle, and accepting that the objective modal landscape is governed by S4, not S5. This explanation implies that evidence about possibility must be conclusive. Although this seems to go against the fact that our modal reasoning is fallible, such fallibility is compatible with our modal justification being conclusive as long as we recognize that an appeal to conclusive evidence can be defeated by Identification Defeaters. 


\section{Reference}

Armstrong, David. 1989. A Combinatorial Theory of Possibility. New York: Cambridge University Press. Bealer, George. 2002. 'Modal Epistemology and the Rationalist Renaissnce.' In Conceivability and Possibility. Edited by Tamar Gendler \& John Hawthorne. 71-126. Oxford: Oxford University Press. Chalmers, David. 2002. 'Does Conceivability Entail Possibility?' In Conceivability and Possibility. Edited by Tamar Gendler \& John Hawthorne. 145-200. Oxford: Oxford University Press

Chandler, Hugh S. 1976. "Plantinga and the Contingently Possible". Analysis 36(2): 106-109.

Clark, Andy. 2013. "Whatever next? Predictive brains, situated agents, and the future of cognitive science". Behavioral and Brain Sciences 36: 181-253.

Fiocco, Marcello Oreste. 2007. 'Conceivability, Imagination, and Modal Knowledge.' Philosophy and Phenomenological Research 74(2): 364-380.

Geirsson, Heimir. 2005. “Conceivability and Defeasible Modal Justification”. Philosophical Studies 122: 279-304.

Hall, Ned. 1994. "Correcting the Guide to Objective Chance”. Mind 103(412): 505-518.

Ichikawa \& Jarvis 2012. 'Rational Imagination and Modal Knowledge.' Noûs 46(1): 127-158.

Ismael, Jenann. 2008. "Raid! Dissolving the Big, Bad Bug”. Noûs 42(2): 292-307.

Jacobs, Jonathan D. 2010. “A Power Theory of Modality: or, How I Learn to Stop Worrying and Reject Possible Worlds”. Philosophical Studies 151: 227-248.

Kind, Amy. 2016. “The Snowman's Imagination”. American Philosophical Quarterly 53(4): 341-348.

Kripke, Saul. 1980. Naming and Necessity. Cambridge: Harvard University Press.

Kung, Peter. 2010. "Imagining as a Guide to Possibility". Philosophy and Phenomenological Research 81(3): 620-663.

Lackey, Jennifer. 2006. “The Nature of Testimony”. Pacific Philosophical Quarterly 87: 177-97.

Lam, Derek. 2018. “Is Imagination too Liberal for Modal Epistemology?” Synthese 195: 2155-2174. 
Levin, Janet. 2011. "Imaginability, Possibility, and the Puzzle of Imaginative Resistance”. Canadian Journal of Philosophy 41(3): 391-421.

Lewis, David. 1980. “A Subjectivist's Guide to Objective Chance”. In Richard C. Jeffrey (ed.) Studies in Inductive Logic and Probability Volume II: 263-293. Berkeley: University of California Press.

Melis, Giacomo. 2014. “Understanding Undermining Defeat”. Philosophical Studies 170: 433-442.

Murray, Adam \& Wilson, Jessica. 2012. "Relativized Metaphysical Modality”. In Oxford Studies in Metaphysics. Edited by Karen Bennett \& Dean Zimmerman. 189-226. Oxford: Oxford University Press.

Peacocke, Christopher. 2003. The Realm of Reason. Oxford: Oxford University Press. _. 1999. Being Known. Oxford: Oxford University Press.

Pettigrew, Richard. 2015. "What Chance-Credence Norms Should Not Be”. Noûs 49(1): 177-196.

Pollock, John. 1987. Contemporary Theories of Knowledge. Lanham: Rowman-Littlefield.

Priest, Graham. 2016. “Thinking the Impossible”. Philosophical Studies 173: 2649-2662.

Roca-Royes, Sonia. 2011. "Essentialism vis-a-vis Possibilia, Modal Logic, and Necessitism”. Philosophy Compass 6(1): 54-64.

_. 2006. "Peacocke’s Principle-Based Account of Modality: 'Flexibility of Origins' Plus S4". Erkenntnis 65(3): 405-426.

Salmon, Nathan. 1989. “The Logic of What Might Have Been”. The Philosophical Review 98(1): 3-34.

Sturgeon, Scott. 2012. "Pollock on Defeasible Reasons”. Philosophical Studies 169: 105-118.

Thau, Michael. 1994. "Undermining and Admissibility”. Mind 103(412): 491-503.

Van Inwagen, Peter. 1998. "Modal Epistemology”. Philosophical Studies 92: 67-84.

Vranas, Peter. 2004. "Have Your Cake and Eat It Too: The Old Principal Principle Reconciled with the New". Philosophy and Phenomenological Research 69(2): 368-382. 
Yablo, Stephen. 1993. "Is Conceivability a Guide to Possibility?” Philosophy and Phenomenological

Research 53(1): 1-42.

Yagisawa, Takashi. 2017. “S4 to S5”. Argumenta 2(2): 241-261. 